\title{
INTERCULTURAL LEARNING ENVIRONMENT IN “AUREL VLAICU” UNIVERSITY
}

\author{
Dorin HERLO, Ph.D., hab. \\ “Aurel Vlaicu” University of Arad, Romania \\ dorinherlo@gmail.com
}

\begin{abstract}
This article seeks to present a few general directions in creating an intercultural learning environment in Higher Education Institutions, with exemplifications from "Aurel Vlaicu" University from Arad. Why? Because Arad City is a multicultural town, our region is in fact a multicultural areal and our students belongs to this county. On the other hand, in the "Aurel Vlaicu" University there are Erasmus+ students from different countries who also bring the nuances of their cultures that interact with ours.
\end{abstract}

Keywords: multiculturality; interculturality; intercultural learning environment; HEI;

\section{Introduction}

Arad, a city situated in the Western part of Romania, with 162,450 inhabitants, with the share of the female population $53.5 \%$ ( 86849 women) and the male population $46.5 \%$ (75601 males), is a multicultural town. In Arad City, the capital of Arad County, there are 78.8\% Romanian, 9.7\% Hungarian, $0.8 \%$ Germans, $1.6 \%$ Gypsies, and 9.2\% other ethnics groups. From the confessions point of view there are: 68.4\% Orthodox, 9.4\% Roman-catholic, 2.5\% Reformat, $0.8 \%$ Greek-catholic, $4.3 \%$ Pentecostals, and $14.6 \%$ other confessions (Toth, 2013).

Arad hosts two universities, a public and a private one, where students from all parts of Romania and from other countries study.

Our University, a public one, named "Aurel Vlaicu" after the pioneer of Romanian flight, enroll more than 10,000 students of different ethnics, confessions and gender, from Romania and from abroad (Republic of Moldavia, Hungary, Serbia) and also host Erasmus + students from Turkey, Portugal, Spain etc. In other words, it is also a multicultural one, like the areal in which it has developed. Those students bring the nuances of their cultures and try to share it and to interact with ours.

In these conditions "Aurel Vlaicu" University has the duty to offer an intercultural learning environment to the students, academics and clerk. Can it? 


\section{Theoretical background}

\section{Motto:}

"People learn best when they feel part of a learning community."

"Aurel Vlaicu" University of Arad, one of 55 Romanian State Universities (and other 46 private Universities) $*$ is called, like any other university, to meet both general and particular requirements to provide an intercultural learning environment, appropriate to a society in globalization.

In this conjuncture, all Higher Education Institutions (HEIs) have the following objectives:

a. To create integrated environments where students of cultural minority backgrounds are not expose to racism and/or discrimination;

b. To actively promote inclusive and interactive teaching technique and research practice;

c. To address the curriculum needs of all those attending Higher Education;

d. To encourage universities' managers to implement policy changes that promotes intercultural learning.

Creating intercultural environments means working in a way that is participatory, experiential and relevant to the interests and energies of the people who are in the room. Therefore, working interculturally involves being open to processes of education where educators and learners work together to learn and thus different ways of knowing are valued in this context.

Any intercultural setting should be one where university staff also grows as part of the process.

In international literature it's mentioned that developing intercultural learning environment in Higher Education Institutions involves adopting certain guidelines across three distinct categories:

1. Reflections on each cultural identity and the assumptions it holds

2. Teaching, learning and research methods.

3. Wider institutional practices and supports

\section{Reflections on each cultural identity and the assumptions it holds}

The most important guideline involves critical reflection on our own cultural and ethnic identity. This includes being open to accepting the prejudices we hold.

How to do that: 
- Reflect on our own worldview and think about how we interpret our own cultural identity;

- Appreciate the multiplicity of our own identities;

- Think about the culturally bound assumptions that shape our interactions with others;

Reflective questions could be:

a) What privileges do I hold (ethnicity, confession, gender, class, race etc.) and what power does this give me?

b) How the life-experiences of my students shape their engagement in the university structures?

c) How do I like to be included where I represent a minority culture?

2. Teaching, learning and research methods.

Education should be problem-posing rather than solution-giving. This means that the role of the educator/facilitator is not to deliver answers, but to facilitate people to step-back from and analyse their own lives so they can decide themselves how best to respond.

Thus, in order to meet these requirements, adopting inclusive and interactive teaching, learning and research methods have to be a normal way in education in this global world.

In this context HEIs must to be aware about:

$>$ The use of language - The most important is to appreciate that language is always evolving and that people should feel free to self-determine their identity rather than be led by the perceptions of others.

$>$ Implementation with determination the interactive teaching \& learning methods - Thus imply creating conditions where students from a variety of backgrounds (social class, gender, ethnicity, confessions, culture etc.) are equally valued and where diversity of experience is recognised and actively incorporated into the learning process.

Talking openly about interculturalism brings diversity alive and reveals a multitude of experiences and perspectives.

For teaching staff (academics), some specific guidelines to guide this approach are:

- Deliberately create opportunities for meaningful cooperative interactions amongst members of different cultural groups; 
Create spaces for students from cultural minority backgrounds to contribute to knowledge creation by sharing their experiences and perspectives;

* Ensure reasonable assessment of learning for students of different cultural groups by using alternative methods of assessment outside of the written papers. (Moore \& Hampton, 2015).

$>$ Curricular changes - Inclusive higher education involves being open to making curricular changes to course materials. These can consist of:

- Ensure that when relevant, curriculum incorporate information about specific cultural groups;

- Ensure that course materials question racialized stereotyping;

- Presentations (e.g. PowerPoints, Prezi etc) should draw from images that reflect cultural diversity as the norm. They should also reflect diversity of gender, age, ethnicity, confessions, race etc.

- Case-studies and other scenarios should incorporate diversity through such things as the names and the gendered roles given to characters.

\section{Wider institutional practices and supports.}

Creating intercultural universities isn't simply about making changes to certain subjects and programs. It is also not simply about changes to the physical environment such as visual displays of diversity, it should be embedded in the practices that inform all aspects of university life.

Higher Education Institutions (HEIs) can relay a message of equality, inclusion and integration to those who attend; both students and visitors. In order to achieve this, some specific guidelines could be:

I. Adherence to Institutional policies on integration - A good starting point is to find out what policies already exist in institutions as, sometimes, staff are unaware of existing policies and recommendations within their own place of work. Where policies are absent, university staff should work to create these policies, ensuring they are in line with national and international recommendations. This could involve creating an institutional working group to develop policy positions and encouraging institutions to organise workshops in inclusive practice.

\section{The physical and social environment}


$\checkmark$ HEIs should actively support the development of student societies

$\checkmark$ Institutions should provide quiet spaces that all students have access to.

$\checkmark$ Institutions should ensure a variety of culinary options that are sensitive to religious and cultural differences.

$\checkmark$ Institutions should ensure appropriate and accessible signage that reflects language diversity.

III. Recognition of International Qualifications and Recognition of Prior Learning - The European Commission requires each HEI to have policies in place on the recognition of both formal and non-formal prior learning. All staff should be familiar with who is responsible for these policies so students can be advised accordingly.

IV. Responding to discrimination and racism - Sometimes discrimination results from "deficit notions" about ethnic or confession minority students or migrant students where, without being consciously aware of it, educators can think of migrant, ethnic or confession students as in some way deficient (Acquah \& Commins, 2016).

To accomplish all these points, HEIs must be very open to all the facts of this world, in a continuously movement, change and transformation and be determined to apply it.

\section{Fingerprints of these concepts in "Aurel Vlaicu" University}

It is obviously that "Aurel Vlaicu" University tries to follow the general objectives for an intercultural learning environment, in a Romanian cultural manner. As we got to know, the general objectives are as it is shown:

1. To create integrated environments where students of cultural minority backgrounds are not exposed to racism and/or discrimination;

2. To actively promote inclusive and interactive teaching technique and research practice;

3. To address the curriculum needs of all those attending Higher Education;

4. To encourage universities' managers to introduce policy changes that promotes intercultural learning. 
We can show how these objectives are realized into our University, analysing them, one by one:

1. In „Aurel Vlaicu” University (UAV), Hungarians, Germans, Serbians, Slovakians etc. being Orthodox, Catholics, Protestants or Agnostics, study together with Romanian students and they are not in any way discriminated! They attend together the learning activities and the practices with the same rights and the same obligations. All academic staff look at their students with empathy, with respect and responsibility. There are also a few Erasmus+ students from Turkey, Portugal... who are familiarised with the Romanian learning system and UAV practices.

2. The academic staff from UAV, following diverse trainings in university didactics/methodology is in the position to deliver interactive and integrate courses, seminars and laboratory activities to improve the learning and the research abilities of the students, without discrimination of ethnicity, confession, race or gender.

3. Generally speaking, our curricula is designed for the needs of our labor market and supervised by internal and external evaluator The Romanian Agency for Quality Assurance in Higher Education (ARACIS), full member of the European Association for Quality Assurance in Higher Education (ENQA). The goals of our curricula are to accomplish employers' requirements (competencies) and for this aim we work for enhancing the learning outcomes of graduated students.

4. University's managers - Rector, Vice Rectors, Deans and Directors - being open minded to the internationalization of the University, try to introduce policy changes that promote intercultural learning at all level of academic and administration.

If in the theoretical part was mentioned that developing intercultural learning environment in Higher Education Institutions involved adopting certain guidelines across three distinct categories:

1. Reflections on each cultural identity and the assumptions it holds

2. Teaching, learning and research methods.

3. Wider institutional practices and supports

we can share some peculiar facts related with our University: 
1. Reflections on each cultural identity and the assumptions it holds - in this direction, at the University level, there is a tradition of 10-12 years in organizing and unfolding the International Interdisciplinary Summer School "Communication and Interculturality", in which the values of the culture of the participants are emphasized and there are workshops realized. During three days of intense activities there are a lot of moments that lead to reflection on our own worldview and thinking about how we interpret our own cultural identity, but, at the same time, in a continuous relation with another culture, with other cultures. Participants from abroad (Moldavia Republic, Ukraina, Serbia, Hungary, Italy, UK, Germany etc) and from other Romanian Universities have a huge input by their presentations. On the other hand, it is a provocative modality for thinking about the boundaries caused by less educated people into intercultural way.

At the level of Faculty of Educational Sciences, Psychology and Social Work there is another traditional event, beginning with 2005, Annual Workshop "Interculturality in contemporary World" which agglutinates effort of the students from master and bachelor study programs. The workshop aims to put the students to think about the culturally bound assumptions that shape their interactions with others. In this workshop the students work together in different kinds of methods like Future Creative Workshop, World Café, Carpatia Role play, Balint group or Future Search Conference, all in the benefit of intercultural learning because the content is around culture, all kind of cultures - theonomous and autonomous.

2. Teaching, learning and research methods. The first important thing in cultural communication is the language used by professors and students, which must be adequate of evolving of the culture.

Firstly, the mother tongue and, immediately next, an international one. In different situations of teaching, learning and evaluation there are different kind of students autochthonous and/or foreigners. The first barrier between cultures is language! For this reason many of our professors and students have the capability to speak correctly the Romanian language and another modern language (English, French, Spanish, and German). It is true that there is a lot of work to be done in this direction but if we want to be chosen by the foreign students we must improve in one foreign language, at least.

The second important thing is that in our University there are conditions for equally treated the students from a variety of backgrounds (social class, gender, ethnicity, confessions, culture etc.) into the learning process, where diversity of experience is recognised and incorporated in an interactive learning methods. Thus professors create opportunities for meaningful cooperative interactions amongst members of different cultural 
groups in their education activities, both formal and non-formal, for sharing their experiences and perspectives. Also academics use alternative methods of assessment like e-portfolio, online questionnaire, observation sheets etc. for students of different cultural groups.

The third important thing is that in our University sustained efforts are made to adapt and update the curriculum to the needs of intercultural society. For example, at the Faculty of Educational Sciences, Psychology and Social Work, there are such preoccupations in this domain, by the proposal of Intercultural education or Intercultural learning courses, at the bachelor level and the master's degree level. In these courses, the curriculum incorporates information on specific cultural groups (ethnics, confessions, gender etc) and ensures materials that question the stereotypes and at the same time proposing very opened debates and panel discussions about discrimination, prejudice or racism.

It's true that there are many things to be done better in the field of research of interculturality, both at the University and at the Faculties level.

3. Wider institutional practices and supports - concerning the requirements of this line, the "Aurel Vlaicu" University as a Higher Education Institution, must relay a message of equality, inclusion and integration to those who attend it, both students and visitors, but it has to make more improvements in this respect. Why do I say that?

Because the staff are unaware of existing policies and recommendations within their own place of work related to the adherence to Institutional policies on integration. In this condition, the university staff should work to create these policies ensuring that they are in line with national and international recommendations. This could involve creating an institutional working group to develop policy positions in inclusive practice.

Secondly, although the University actively supports the development of student society (encouraging the Students' league and their activities) and ensures enough spaces that all students have access to, it isn't sensitive to ensure a variety of culinary options for difference cultural groups or not provide appropriate and accessible signage that reflects language diversity.

But, from another point of view, the academic staff of our University is prepared to respond to discrimination, results from "deficit notions" about ethnic or confession minority students. They all have respect of diversity and responsibility for each human been.

Whilst the European Commission requires each HEI to have policies in place on the recognition of both formal and non-formal prior learning, our University is not prepared for the second one. It's true that, generally speaking, no University from Romania is prepared for this thing. 


\section{Conclusions}

Higher Education Institutions must accomplish some specific guidelines and objectives into the global society for being and offering an intercultural learning environment.

From this point of view "Aurel Vlaicu" University of Arad tries to be in this trend, where creating intercultural environments means working in a way that is participatory, experiential and relevant to the interests and energies of the academic staff and students who are under the same roof.

Thinking and working interculturally means being open to the processes of education where academic staff and students work together to learn, sharing learning situations and wining learning experiences and thus different ways of knowing are valued in this context.

And we can conclude now that an intercultural setting should be one where academic staff and students grow as part of the process, contributing as well to organization's culture.

\section{References}

Acquah EO, Commins, N. L., (2016), International students' perspectives of a diverse class on multiculturalism, in Journal of Further and Higher Education, $29 \quad$ Sept. 2016, pp 1-12, http://dx.doi.org/10.1080/0309877X.2016.1224328

European Union (EU), (2004), Common Basic Principles http://www.eesc.europa.eu/resources/docs/common-basicprinciples_en.pdf, accessed at 27-th April, 2018

Moore, P., Hampton, G., (2015), "It's a bit of a generalisation, but...: participant perspectives on intercultural group assessment in higher education", Assessment and Evaluation in Higher Education, 40 (3), 390406.

Toth, G., (2013), Studiu de fundamentare privind evoluţia sociodemografică, Actualizare Plan Urbanistic General Municipiul Arad. Primăria Arad.

*ARACIS (The Romanian Agency for Quality Assurance in Higher Education), (2017), HEIs Statistics, Bucharest 